\title{
Development of New Negative-tone Molecular Resists Based on Calixarene for EUV Lithography
}

\author{
Hiroaki Oizumi, Takafumi Kumise, and Toshiro Itani \\ Semiconductor Leading Edge Technologies, Inc. (Selete) \\ 16-1 Onogawa, Tsukuba, Ibaraki 305-8569, Japan
}

\begin{abstract}
We have developed new negative-tone molecular resists based on phenyl calix[4]resorcinarene derivatives, and evaluated their EUV patterning performance. EUV imaging experiments were performed using the high-numerical-aperture $(\mathrm{NA}=0.3)$, smallfield EUV exposure tool (HINA). Patterning results showed the resolution of the resist on an organic layer substrate to be $29 \mathrm{~nm}$ at an EUV exposure dose of $22.2 \mathrm{~mJ} / \mathrm{cm}^{2}$ and the obtainable aspect ratio to be as high as 2 , with pattern collapse being markedly suppressed. In addition, we analyzed the outgassing of the resists during EUV exposure. The outgassing rates of the new resins were on the same order as that of conventional poly(phydroxystylene) (PHS) resin. On the other hand, the outgassing rates of the new resists were about five times higher than that of conventional PHS-based resist. Quadropole mass spectra showed the main source of resist outgassing to be EUV-induced decomposition of the photoacid generator.
\end{abstract}

Keywords: EUV lithography, molecular resist, calix[4]resorcinarene, outgassing

\section{Introduction}

One of the most significant benefits of EUV lithography (EUVL) is that it is extendable to multiple technology rules $(32 \mathrm{~nm}, 22 \mathrm{~nm}$, and below). For the 32-nm rule and below, a difficult problem arises in that all the resist requirements (sub-30-nm resolution, high sensitivity, small line edge roughness (LER), no pattern collapse, and low outgassing) must be satisfied at the same time. At present, the development of high-quality EUV resists is one of top three critical issues in EUVL [1].

Considering resist materials, conventional polymeric chemically amplified (CA) resists have reached their performance limit [2]: The resolution is limited by acid diffusion, and the LER is too large due to the large molecules and compositional non-uniformity.

It is presumed that the cause of LER from the standpoint of the resist material is non-uniform dissolution, which gives rise to "aggregates" in the resist side wall $[3,4]$. A promising solution is molecular resists, which have two strong points concerning reduction of the LER: One is the intrinsically small size of the molecules, which results in small "aggregates" and a small LER; and the other is monodispersion, which provides uniform dissolution and a small LER. In addition, regarding the properties of resist film, monodispersion is able to directly provide the designed function of a designed molecular structure. A large number of them have been investigated in the search for a suitable one [5-33].

Many papers have reported molecular resist systems based on various methyl calix[4] resorcinarene derivatives. However, the adhesion of such resists to a silicon wafer is rather poor; and in standard developer, the development rate is very high, necessitating either an extremely short development time or the use of dilute developer [8, $9,15,18,20,21]$.

Recently, the Cornell University group reported the good performance of positive-tone molecular resists based on partially protected ptert-butyl-phenylcalix[4]resorcinarene derivatives in a process employing standard developer [22].

Generally speaking, positive-tone resists are more widely used than negative-tone ones in conventional optical lithography for LSI manufacturing. In EUVL, however, negative-tone resists may be better for delineating isolated patterns, such as those for the gate layer, because the serious issue of flare control makes a dark-field mask pattern preferable.

In this study, we developed new negativetone molecular resists based on phenylcalix[4] resorcinarene derivatives, and evaluated both their EUV patterning performance and their outgassing characteristics during EUV exposure.

$\begin{array}{llrl}\text { Received } & \text { May } & 7, & 2008 \\ \text { Accepted } & \text { June } & 13, & 2008\end{array}$




\section{Experiments}

\subsection{Materials}

Precursor: resorcinol (Kanto Chemical) and aromatic aldehyde derivatives (Mitsubishi Gas Chemical)

Photoacid generator (PAG): triphenylsulfonium perfluoro-1-butanesulfonate (TPS-PFBS, Midori Kagaku) and diphenylsulfonium p-toluene sulfonate (DPTMPS-PTS, Wako Pure Chemical Industries)

Cross-linker: hexamethoxymethylmelamine (MW-100LM, Sanwa Chemical)

Quencher: 2, 4, 5-Triphenyl-imidasole, (TPI, Kanto Chemical)

Casting solvent: propylene glycol monomethyl ether (PGME, Kanto Chemical)

Developer: aqueous solution of tetramethyl ammonium hydroxide (TMAHaq, Tokyo Ohka Kogyo)

Reference polymer: poly(p-hydroxystylene) (PHS, $\mathrm{Mw}=8000$, Aldrich)

\subsection{Synthesis of phenylcalix[4]resorcinarene} derivatives

The phenylcalix[4]resorcinarene derivatives were synthesized from resorcinol and a kind of aromatic aldehyde, as shown in Scheme 1.

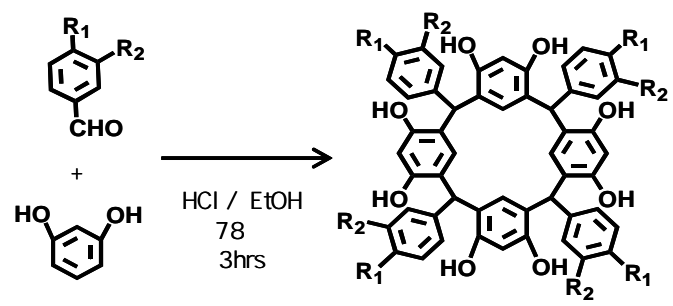

$\mathrm{R}_{1}$ : methyl, phenyl, n-propyl, i-butyl, i-propyl, cyclohexyl, or 4-n-propylcyclohexyl

$\mathrm{R}_{2}$ : $\mathrm{H}$ or methyl

Scheme 1

2.3 Formation of new negative-tone molecular resists

We first examined the solubility of phenylcalix[4]resorcinarene derivatives in PGME and $0.26 \mathrm{~N}$ TMAHaq (Table 1): C-4isopropylphenylcalix[4]resorcinarene (MGR104) and C-4-cycrohexylphenylcalix[4] resorcinarene (MGR108) showed good solubility in both PGME and $0.26 \mathrm{~N}$ TMAHaq. Fig. 1 and 2 show the chemical structures and stable conformations of the new resins MGR104 and MGR108, respectively, yielded by molecular mechanics (MM2) calculations. The molecules of each resin are at most $2 \mathrm{~nm}$ long, which makes them suitable for a new negative-tone molecular resist system. Three advanced chemically-amplified (CA) resists (labeled A, B, and C) were prepared from four components: MGR104 or MGR108, a PAG, a quencher, and a cross-linker (Table 2).

Table 1. Solubility of phenylcalix[4]resorcinarene derivatives in PGME $^{\text {a) }}$ and $0.26 \mathrm{~N}^{\text {TMAHaq }}{ }^{\text {b) }}$

\begin{tabular}{|c|c|c|c|}
\hline R1 & R2 & PGME & 0.26 NMAHaq \\
\hline methyl & H & Insoluble & N/A \\
\hline methyl & methyl & Insoluble & N/A \\
\hline phenyl & H & Insoluble & N/A \\
\hline n-propyl & H & Barely soluble & Soluble \\
\hline i-butyl & H & Barely soluble & Soluble \\
\hline i-propyl & H & Soluble & Soluble \\
\hline cyclohexyl & H & Soluble & Soluble \\
\hline 4-n-propylcyclohexyl & H & Soluble & Insoluble \\
\hline
\end{tabular}

a. Insoluble: < $2 \mathrm{wt} \%$; Barely soluble: $2-5 \mathrm{wt} \%$; Soluble: $>5 \mathrm{wt} \%$

b. Insoluble: $<5 \mathrm{~nm} / \mathrm{min}$; Soluble: $>50 \mathrm{~nm} / \mathrm{min}$
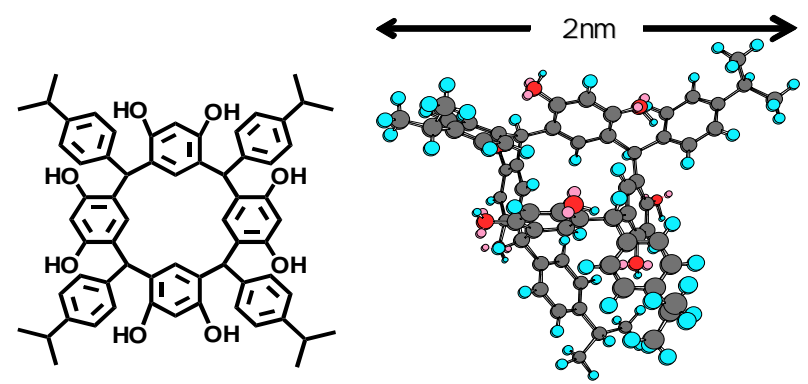

Fig. 1. Chemical structure and stable conformation of C-4-isopropylphenylcalix[4]resorcinarene (MGR104).

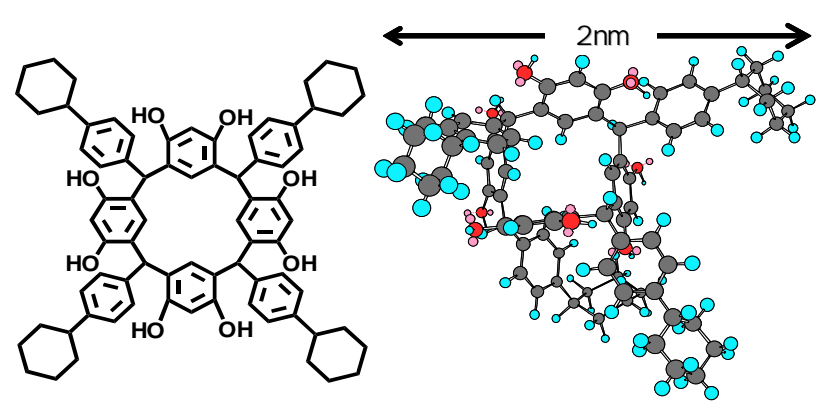

Fig. 2. Chemical structure and stable conformation of $C$ 4-cycrohexylphenylcalix[4]resorcinarene (MGR108).

Table 2. Components of new molecular resist systems.

\begin{tabular}{|c|c|c|c|c|}
\hline & Resin & PAG & Quencher & Cross-rinker \\
\hline Resist A & MGR104 & TPS-PFBS & TPI & MW-100LM \\
\hline Resist B & MGR104 & DPTMP-pTS & TPI & MW-100LM \\
\hline Resist C & MGR108 & TPS-PFBS & TPI & MW-100LM \\
\hline
\end{tabular}




\subsection{Lithographic evaluation}

To evaluate the sensitivity of EUV resists, we used an EUV flood-exposure tool [28]. The light source was a synchrotron radiation (SR) beam on the SBL-2 beamline of Super-ALIS at NTT [36]. A pair of grazing-incidence toroidal mirrors was installed near the front of SBL-2 to deliver and collimate the SR beam. The grazing angles of both were $2.5^{\circ}$. The tool was installed at the end station of SBL-2 and was equipped with a planar folding mirror, a $\mathrm{Zr}$ filter, an xy-wafer stage, and a loadlock mechanism in a vacuum chamber. The SR beam. was incident on the folding mirror at an angle of $45^{\circ}$, and the reflected beam passed through the $\mathrm{Zr}$ filter to eliminate out-of-band light before arriving at the wafer. The mirror was coated with a 40-pair Mo/Si multilayer, which selects the band around $13.5 \mathrm{~nm}$. The EUV exposure area was a circle $7 \mathrm{~mm}$ in diameter, and the EUV intensity on a resist was $0.4 \sim 1.8 \mathrm{~mW} / \mathrm{cm}^{2}$.

Imaging experiments were performed using the high-numerical-aperture $(\mathrm{NA}=0.3)$, smallfield EUV exposure tool (HINA) [34, 35]. HINA is equipped with an illumination system, projection optics, a mask stage, and a wafer stage in a vacuum chamber. The EUV light source was an SR beam on beamline SBL-1 of Super-ALIS. The exposure wavelength was $13.5 \mathrm{~nm}$. The projection optics consist of two aspherical mirrors. The imaging field is $0.3 \mathrm{~mm} \times 0.5 \mathrm{~mm}$ in size. The RMS wave front error (WFE) of the projection optics is $0.9 \mathrm{~nm}$ $[37,38]$.

HINA has both coherent and partially coherent illumination systems. The coherent one consists of two flat mirrors and a spherical mirror, which focuses the image of the EUV light source on a point at the pupil of the projection optics. The advantage of this system is that the image that it forms has a higher contrast than that obtainable with the partially coherent illumination system. So, we used it to investigate the ultimate fine-pitch patterning performance of the resist. The cut-off pattern half-pitch (hp) under three-ray interference is $28 \mathrm{~nm}$ for L\&S patterns [35].

The EUV mask used in the experiments had an 80-nm-thick TaGeN absorber and a 10-nm-thick Cr buffer layer [39-41]. Sample resist films were spin-coated on either a silicon wafer or an organiclayer substrate and subjected to a post-application bake on a hot plate at a temperature of $110^{\circ} \mathrm{C}$ for $90 \mathrm{~s}$. Following EUV exposure, the films were subjected to a post-exposure bake (PEB) at a temperature of $110^{\circ} \mathrm{C}$ for $90 \mathrm{~s}$, developed in $0.26 \mathrm{~N}$
TMAHaq for $30 \mathrm{~s}$, and rinsed in deionized $\mathrm{H}_{2} \mathrm{O}$ without a surfactant for $30 \mathrm{~s}$ using an off-line coater $\&$ developer system.

\subsection{Measurements}

FT-IR spectra of resist films were measured with a spectrometer (FTS-55A, Bio-Rad Digilab) by the attenuated-total-reflection method. The thickness of the films ranged from $50 \mathrm{~nm}$ to 100 $\mathrm{nm}$, as determined with a multiwavelength interference thickness measurement system (M5100A, Nanometrics). Top-down images were taken with a critical-dimension (CD) SEM (S-8840, Hitachi).

Apparatus to evaluate EUV resist outgassing was installed on the SBL-2. It included a folding planar mirror, $\mathrm{Zr}$ filters, wafer stages, BayardAlpert gauges (Granville-Phillips), a quadropole mass analyzer (M-200QA, ANELVA), and a loadlock mechanism in a vacuum chamber. The SR beam was incident on the folding planar mirror at an angle of $45^{\circ}$ and passed through the $\mathrm{Zr}$ filter before reaching the resist.

The EUV exposure area was a $10 \mathrm{~mm} \times 20$ $\mathrm{mm}$ rectangle, and the EUV intensity on a resist was $0.01 \sim 2.0 \mathrm{~mW} / \mathrm{cm}^{2}$. The background pressure of the chamber was less than $1 \times 10^{-7} \mathrm{~Pa}$. The outgassing rates of resists in the steady state were determined by the pressure rise method, in which the outgassing rate is taken to be equal to the pumping-down speed during EUV exposure [31].

\section{Results and Discussion}

\subsection{FT-IR spectra}

Fig. 3 shows FT-IR spectra of resist $\mathrm{C}$ before and after exposure, and their difference. After EUV exposure at a dose of $50 \mathrm{~mJ} / \mathrm{cm}^{2}$ and PEB at $110^{\circ} \mathrm{C}$ for $90 \mathrm{~s}$, the absorbance of the $980-\mathrm{cm}^{-1}$ band increased, which indicates the formation of an ether peak by a reaction between the crosslinker, hexamethoxymethylmelamine, and the oalkylation of the phenolic structure [42]. Thus, EUV exposure makes the resist system work in a negative fashion.

\subsection{Resist sensitivity}

Fig. 4 shows EUV sensitivity curves for the three new molecular CA resists (A, B, C). All exhibit negative-tone characteristics: and the exposure doses providing a remaining thickness of $90 \%\left(E_{90}\right)$ were 71,53 and $20 \mathrm{~mJ} / \mathrm{cm}^{2}$, respectively. Resists A and B showed poor sensitivity and no remaining thickness over $90 \%$, even for an 
overdose, such as $100 \mathrm{~mJ} / \mathrm{cm}^{2}$. On the other hand, resist $\mathrm{C}$ showed moderate sensitivity and a good, steep curve, indicating that it should exhibit good lithographic performance.

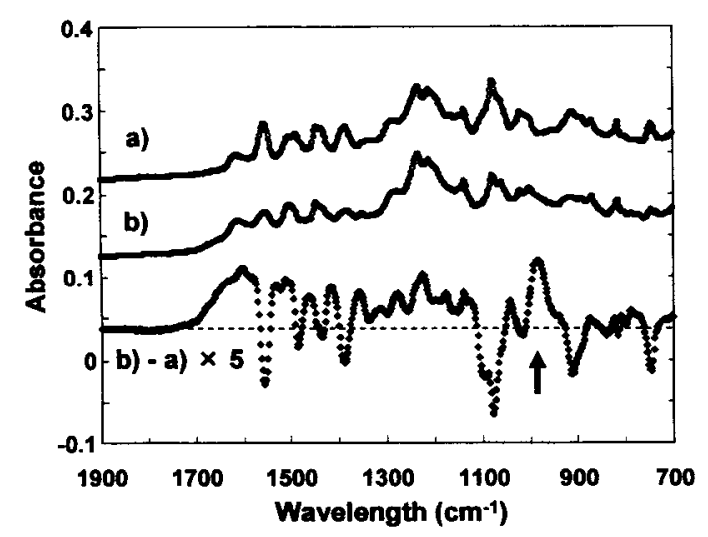

Fig. 3. FT-IR spectra of resist C film: a) before exposure (as-coated), b) after EUV exposure at dose of $50 \mathrm{~mJ} / \mathrm{cm}^{2}$ and $\mathrm{PEB}$ at $110^{\circ} \mathrm{C}$ for $90 \mathrm{~s}$, and their difference (expanded 5x).

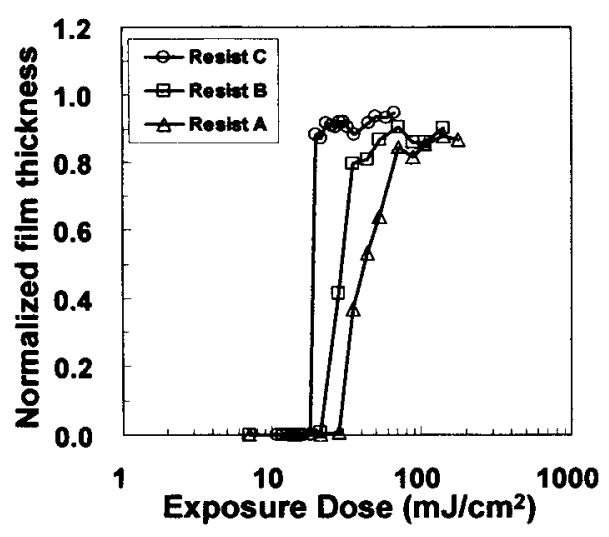

Fig. 4. EUV sensitivity curves for three new negativetone $\mathrm{CA}$ resists $(\mathrm{A}, \mathrm{B}, \mathrm{C})$.

\subsection{Fine-pitch patterning}

Fig. 5 shows top views of dense lines with half pitches of 55, 50, 45, and $40 \mathrm{~nm}$ printed in a 55-nm-thick layer of resist $B$, which is based on MGR104, at an EUV exposure dose of $41 \mathrm{~mJ} / \mathrm{cm}^{2}$. Neither the resolution for $50 \mathrm{~nm}$ nor the sensitivity are satisfactory. One possible reason for the somewhat poor performance is the high development rate of the base resin, $C-4$ isopropylphenyl calix[4]resorcinarene in standard developer, $0.26 \mathrm{~N}$ TMAHaq.

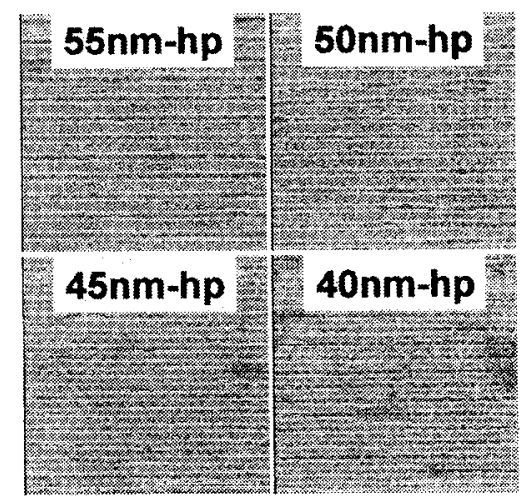

Fig. 5. Top view of dense line patterns with CDs ranging from 55 to $40 \mathrm{~nm}$, printed in 55-nm-thick layer of resist $\mathrm{B}$, which is based on $C$-4-isopropylphenylcalix [4]resorcinarene (MGR104), at EUV exposure dose of $41 \mathrm{~mJ} / \mathrm{cm}^{2}$. (hp = half pitch)

Fig. 6 shows top views of dense lines with half pitches of $45,40,35,32,30$, and $29 \mathrm{~nm}$ printed in a 60-nm-thick layer of resist $\mathrm{C}$, which is based on MGR108, at an EUV exposure dose of $26.4 \mathrm{~mJ} / \mathrm{cm}^{2}$. The resolution is less than $30 \mathrm{~nm}$ while the sensitivity is higher than that of resist $A$. Unfortunately, resist patterns with a half pitch of around $30 \mathrm{~nm}$ collapsed.

Fig. 7 shows top views of dense lines with half pitches of $45,40,35,32,30$ and $29 \mathrm{~nm}$ printed in a 60-nm-thick layer of resist $\mathrm{C}$ on an organiclayer substrate at an EUV exposure dose of 22.7 $\mathrm{mJ} / \mathrm{cm}^{2}$. The patterns did not collapse, even for a half pitch of around $30 \mathrm{~nm}$ and a high aspect ratio (AR) of about 2 .

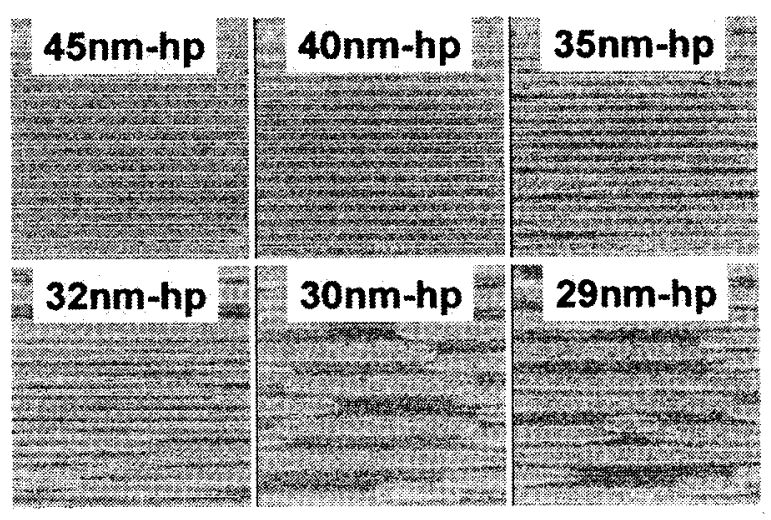

Fig. 6. Top view of dense line patterns with CDs ranging from 45 to $29 \mathrm{~nm}$, printed in $60-\mathrm{nm}$-thick layer of resist $\mathrm{C}$, which is based on C-4-cycrohexylphenylcalix[4] resorcinarene (MGR108), at an EUV exposure dose of $26.4 \mathrm{~mJ} / \mathrm{cm}^{2}$. (hp = half pitch) 


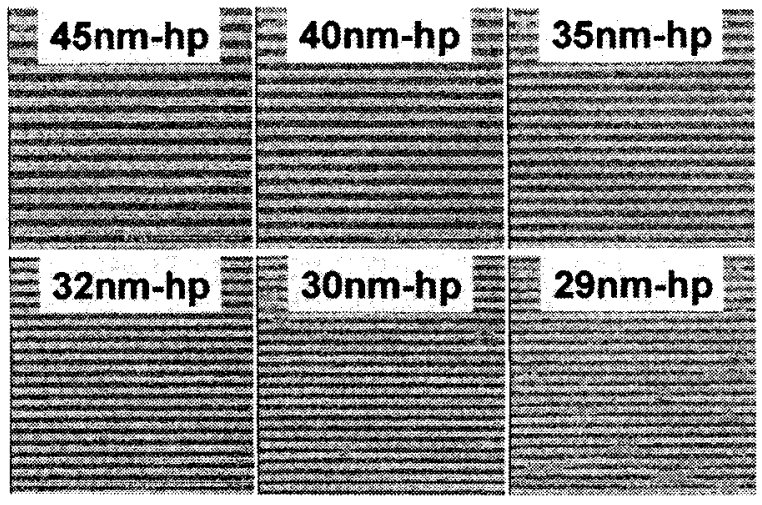

Fig. 7. Top view of dense line patterns with CDs ranging from 45 to $29 \mathrm{~nm}$, printed in 60 -nm-thick layer of resist $\mathrm{C}$ on an organic-layer substrate at an EUV exposure dose of $26.4 \mathrm{~mJ} / \mathrm{cm}^{2}$. (hp = half pitch)

\subsection{Analysis of resist outgassing}

Fig. 8 shows the typical pressure rise due to outgassing from resist $\mathrm{C}$ and its resin (MGR108) as a function of EUV exposure time at an EUV intensity of about $0.5 \mathrm{~mW} / \mathrm{cm}^{2}$. After $16 \mathrm{~s}$, the chamber pressure reached the steady state, or in other words, the outgassing rate became equal to the actual pumping-down rate. So, the outgassing rate can be estimated from the actual pumpingdown rate and the pressure rise in the steady state. After the steady state, the pressure rise gradually decreased. On the other hand, for the resin (MGR108) film, the pressure rose only slightly at the start of EUV exposure and then hardly changed at all during exposure. These behaviors suggest that the main EUV-induced decomposition species are different for resist $\mathrm{C}$ and the resin.

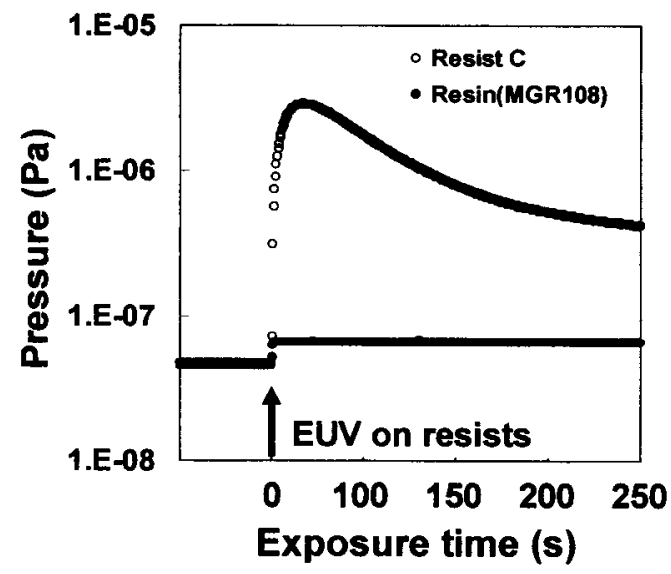

Fig. 8. Typical pressure rise due to outgassing from resist $\mathrm{C}$, which is based on MGR108, and its resin (MGR108) as a function of EUV exposure time.
Table 3 lists the outgassing rates of the three resists (A, B, C), their resins (MGR108, MGR104), a typical PHS-based KrF resist, and PHS in the steady state during EUV irradiation. The outgassing rates have been converted to equivalent values for the $400-\mathrm{mW} / \mathrm{cm}^{2}$ EUV intensity of a mass-production exposure tool. The outgassing rate of the new molecular resist resins is on the same order as that of a conventional polymeric PHS resin. Unfortunately, the outgassing rates of the new molecular resists were about 5 times higher than that of a conventional polymeric $\mathrm{KrF}$ resist.

Fig. 9 shows quadropole mass spectra of the species outgassed from MGR108, PHS and resist C films during EUV exposure. The spectra for PHS and MGR108 are almost the same and show no mass numbers over 44 . These results indicate that MGR108 is as stable as PHS under EUV irradiation.

The mass spectrum of resist $\mathrm{C}$ shows much larger counts for mass numbers over 44 (48 53, $60 \sim 64,69 \sim 70,72 \sim 81)$ than either MGR108 or PHS. These fragments may be attributable to hydrocarbons $\left(\mathrm{C}_{x} \mathrm{H}_{y}\right)$, hydrofluorocarbons $\left(\mathrm{C}_{x} \mathrm{H}_{y} \mathrm{~F}_{z}\right)$, benzene derivatives, and sulfur oxide derivatives $\left(\mathrm{SO}_{\mathbf{x}}\right)$, which are the decomposition species of the PAG (TPS-PFBS). So, the main reason for the heavy outgassing of resist $\mathrm{C}$ is the decomposition of the PAG caused by EUV exposure.

Table 3. Outgassing rates of resist films in the steady state during EUV irradiation. The rates have been converted to equivalent values for the $400-\mathrm{mW} / \mathrm{cm}^{2}$ EUV intensity of a mass-production exposure tool.

\begin{tabular}{|c|c|}
\hline Sample & $\begin{array}{c}\text { Outgassing rate } \\
\text { (molecules } / \mathrm{cm}^{2} / \mathrm{s} \text { ) at } \\
400 \mathrm{~mW} / \mathrm{cm}^{2}\end{array}$ \\
\hline Resin (MGR104) & $4.7 \times 10^{14}$ \\
\hline Resist A & $3.2 \times 10^{16}$ \\
\hline Resist B & $1.8 \times 10^{16}$ \\
\hline Resin (MGR108) & $3.3 \times 10^{14}$ \\
\hline Resist C & $3.8 \times 10^{16}$ \\
\hline KrF resist * & $6.0 \times 10^{15}$ \\
\hline Resin (PHS) & $2.9 \times 10^{14}$ \\
\hline
\end{tabular}

*Ref. 31) 

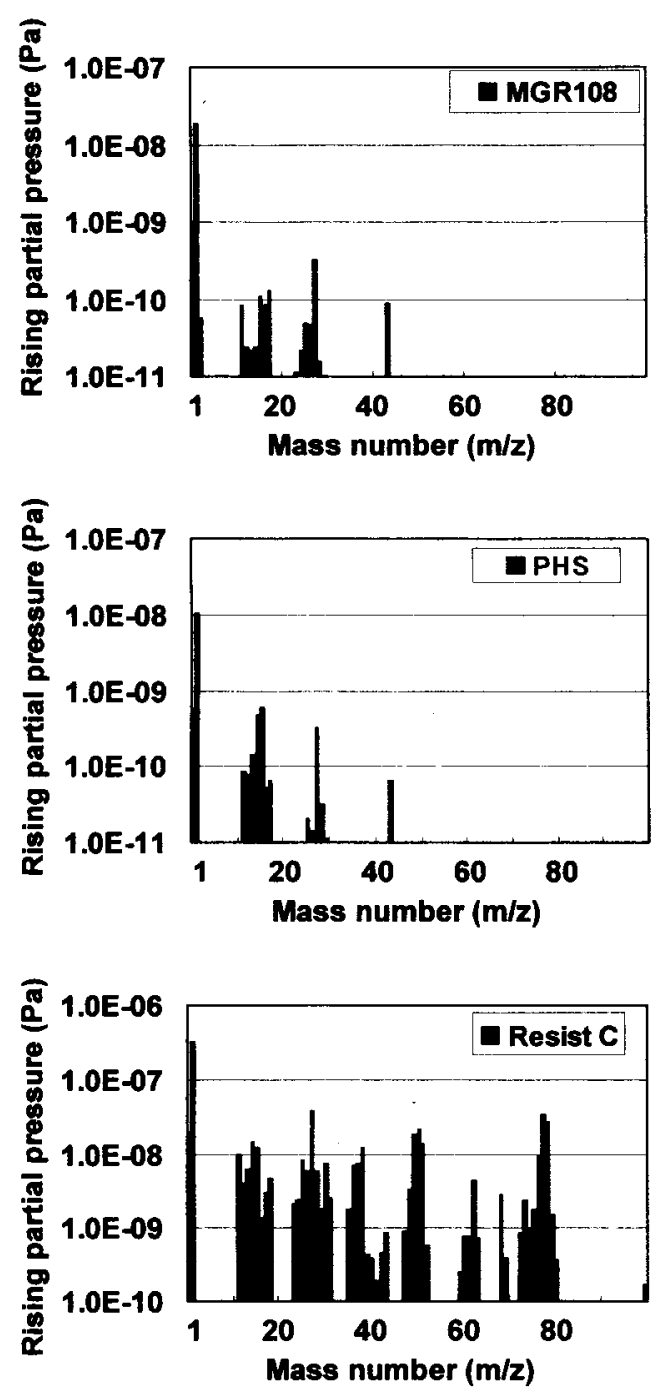

Fig. 9. Quadropole mass spectra of species outgassed from MGR108, PHS, and resist C films during EUV exposure.

\section{Conclusions}

We developed new negative-tone molecular resists based on phenyl calix[4]resorcinarene derivatives and evaluated their EUV patterning performance. The patterning results for resist $\mathrm{C}$, which is based on C-4-cycrohexylphenylcalix [4] resorcinarene (MGR108), on an organic layer substrate showed the resolution to be $29 \mathrm{~nm}$ at an EUV exposure dose of $22.2 \mathrm{~mJ} / \mathrm{cm}^{2}$, and the obtainable aspect ratio to be as high as 2 .

The outgassing rates of the new resins were on the same order as that of a conventional resin, PHS. On the other hand, the outgassing rates of the new molecular resists were about 5 times higher than that of a conventional PHS-based resist. The main cause of resist outgassing is the EUVinduced decomposition of the PAG.
If a low-outgassing PAG can be applied, this molecular resist system has the potential to meet the strict resist requirements for the $32-\mathrm{nm}$ technology node and beyond.

\section{Acknowledgments}

The authors would like to thank to Mr. M. Echigo and Mr. D. Oguro of Mitsubishi Gas Chemical Company, Inc. for useful discussions and for the preparation of the new molecular resists. The authors would also like to thank the member companies of Selete (EUV Lithomask Program) for their continued support. In addition, the authors are very grateful to Dai Nippon Printing Co., Ltd. for fabricating the mask, and to Nikon Corporation for useful discussions and for developing and providing the HINA set-3 optics.

This work was partially supported by the New Energy and Industrial Technology Development Organization (NEDO).

\section{References}

1. K. Kemp, presented at the 4th International EUV Symposium, 7-9 November, 2005, San Diego.

2. W. Hinsberg, F. Houle, M. Sanchez, J. Hoffnagle, G. Wallraff, D. Medeiros, G. Gallatin and J. Cobb, Proc. SPIE, 5039 (2003) 1.

3. T. Yoshimura, H. Shiraishi, J. Yamamoto and $\mathrm{S}$.

Okazaki, Appl. Phys. Lett., 63 (1993) 764.

4. H. Namatsu, M. Nagase, T. Yamaguchi, K. Yamazaki and K. Kurihara, J. Vac. Sci. Technol., B16 (1998) 3315.

5. J. Fujita, Y. Ohnishi, Y. Ochiai and S. Matsui, Appl. Phys. Lett., 68 (1996) 1297.

6. T. Tada and T. Kanayama, Jpn. J. Appl. Phys., 35 (1996) L63.

7. M. Yoshiiwa, H. Kageyama, Y. Shirota, F. Wakaya, K. Gamo and M. Takai, Appl. Phys. Lett., 69 (1996) 2605.

8. T. Nakayama, K. Haga, O. Haba and M. Ueda, Chem. Lett., 265 (1997).

9. M. Ueda, D. Takahashi, T. Nakayama and O. Haba,

Chem. Mater., 10 (1998) 2230.

10. N. Kihara, S. Saito, T. Ushirogouchi and M. Nakase,

J. Photopolym. Sci. Technol., 11 (1998) 553.

11. S. Uchino, J. Yamamoto, S. Migitaka, K. Kojima, M. Hashimoto and H. Shiraishi, J. Vac. Sci. Technol., B16 (1998) 3684. 
12. A. P. G. Robinson, R. E. Palmer, T. Tada, T. Kanayama, M. T. Allen and J. A. Preece, Appl. Phys. Lett., 72 (1998) 1302.

13. D. C. Tully, A. R. Trimble and J. M. J. Frechet, Adv. Mater., 12 (2000) 1118.

14. T. Kadota, M. Yoshiiwa, H. Kageyama, F. Wakaya, K. Gamo and Y. Shirota, Proc. SPIE, 4345 (2001) 891.

15. T. Nishikubo and A. Kameyama, J. Polym. Sci. Part A. Polym. Chem., 39 (2001) 1481.

16. J.-B. Kim, H.-J. Yun and Y.-G. Kwon, Chem. Lett., 10 (2002) 1064.

17. S. Saito, N. Kihara and T. Ushirogouchi, Microelectron. Eng., 61-62 (2002) 777.

18. H. Iimori, Y. Shibasaki, M. Ueda and H. Ishii, J. Photopolym. Sci. Technol., 16 (2003) 685.

19. T. Hirayama, D. Shiono, H. Hada, J. Onodera and $M$. Ueda, J. Photopolym. Sci. Technol., 17 (2004) 435.

20. S. Chang, D. Yang, J. Dai, N. Felix, D. Bratton, K. Tsuchiya, Y. Kwark, J. Bravo, C. Ober, H. Cao and H. Deng, Proc SPIE, 5753 (2005) 5.

21. R. Ramakrishnan, S. Chang, N. Felix, H. Cao, H. Deng, W. Yueh and C. Ober, J. Photopolym. Sci. Technol., 19 (2006) 515.

22. D. Bratton, R. Ayothi, N. Felix, H. Cao, H. Deng, C. Ober, Proc. SPIE, 6153 (2006) 61531D-1.

23. D. Shiono, T. Hirayama, H. Hada, J. Onodera, T. Arai, T. Sakamizu, A. Yamaguchi, K. Kojima, H. Shiraishi and H. Fukuda, Jpn. J. Appl. Phys., 45 (2006) 5435.

24. A. P. G. Robinson, H. M. Zaid, F. P. Gibbons, R. E. Palmer, M. Manickam, J. A. Preece, R. Brainard, T. Zampini and K. O'Connell, Microelectron. Eng., 83 (2006) 1115.

25. S. Tanaka and C. Ober, Proc. SPIE, 6753 (2006) 67532B-1.

26. K. Kojima, T. Hattori, H. Fukuda, T. Hirayama, D. Shiono, H. Hada and J. Onodera, J. Photopolym. Sci. Technol., 19 (2006) 373.

27. H. Oizumi, F. Kumasaka, Y. Tanaka, T. Hirayama, D. Shiono, H. Hada, J. Onodera, A. Yamaguchi and I. Nishiyama, Microelectron. Eng., 83 (2006) 1107

28. H. Oizumi, Y. Tanaka, D. Shiono, T. Hirayama, H. Hada, J. Onodera, A. Yamaguchi and I. Nishiyama, J. Photopolym. Sci. Technol., 19 (2006) 507.

29. D. Shiono, H. Hada, T. Hirayama, J. Onodera, H. Oizumi, 1. Nishiyama, K. Kojima, A.
Yamaguchi and H. Fukuda, Microelectron. Eng., 84 (2007) 1084.

30. H. Oizumi, F. Kumasaka, Y. Tanaka, T. Hirayama, D. Shiono, H. Hada, J. Onodera, A. Yamaguchi, I. Nishiyama, Microelectron. Eng., 84 (2007) 1049.

31. H. Oizumi, Y. Tanaka, T. Kumise, D. Shiono, T. Hirayama, H. Hada, J. Onodera, A. Yamaguchi, and I. Nishiyama, J. Photopolym. Sci. Technol., 20 (2007) 403.

32. X. André, J. Lee, A. De Silva, N. Felix, C. Ober, H. Cao, H. Deng, H. Kudo, D. Watanabe, $\mathrm{T}$. Nishikubo, Proc. SPIE, 6519 (2007) 65194B-1.

33. D. Shimizu, K. Maruyama, A. Saitou, T. Kai, T. Shimokawa, K. Fujiwara, Y. Kikuchi and I. Nishiyama, J. Photopolym. Sci. Technol., 20 (2007) 423.

34. H. Oizumi, Y. Tanaka, F. Kumasaka, I. Nishiyama, H. Kondo, M. Shiraishi, T. Oshino, K. Sugisaki and K. Murakami, Proc. SPIE, 5751 (2005) 102.

35. H. Oizumi, Y. Tanaka, F. Kumasaka, and I. Nishiyama,

Proc. SPIE, 6151 (2006) 61512Q-1.

36. T. Hosokawa, T. Kitayama, T. Hayasaka, S. Ido, Y. Uno, A. Shibayama, J. Nakata, K. Nishimura and $M$. Nakajima, Rev. Sci. Instrum., 60 (1989) 1783.

37. T. Oshino, M. Shiraishi, N. Kandaka, K. Sugisaki, H. Kondo, K. Ota, K. Mashima, K. Murakami, H. Oizumi, I. Nishiyama and S. Okazaki, Proc. SPIE, 5037 (2003) 75.

38. T. Oshino, S. Takahashi, T. Yamamoto, T. Miyoshi, M. Shiraishi, T. Komiya, N. Kandaka, H. Kondo, K. Mashima, K. Nomura, K. Murakami, T. Okuyama, H. Oizumi, I. Nishiyama and S. Okazaki, J. Vac. Sci. Technol., B22 (2004) 2975.

39. T. Abe, M. Nishiguchi, T. Amano, T. Motonaga, S. Sasaki, H. Mohri, N. Hayashi, Y. Tanaka, H. Yamanashi and I. Nishiyama, Proc. SPIE, 5446 (2004) 832.

40. Y. Tanaka, I. Nishiyama, T. Abe, S. Sasaki and $\mathrm{N}$. Hayashi, Proc. SPIE, 5567 (2004) 1377.

41. T. Abe, M. Nishiguchi, T. Amano, T. Motonaga, S. Sasaki, H. Mohri, N. Hayashi, Y. Tanaka and I. Nishiyama, Proc. SPIE, 5567 (2004) 1435.

42. J. W. Thackeray, G. W. Orsula, M. M. Rajaratnam, R. Sinta, D. Herr and E. Pavelcheck, Proc. SPIE, 1466 (1991) 39. 